\title{
In situ characterization of temperature and gas production using membrane interface probe (MIP) and hydraulic profiling tool (HPT) in an operating municipal solid waste landfill
}

\author{
M. Sina Mousavi ${ }^{1}$, Yuan Feng ${ }^{1}$, Mostafa Afzalian ${ }^{1}$, Josh McCann ${ }^{2}$ and Jongwan Eun ${ }^{*}, 3$ \\ ${ }^{1} \mathrm{PhD}$ Student, Civil Engineering, University of Nebraska-Lincoln, Lincoln, NE, USA \\ ${ }^{2}$ Undergraduate Student, Civil Engineering, University of Nebraska-Lincoln, Lincoln, NE, USA \\ ${ }^{3}$ Assistant Professor, Civil Engineering, University of Nebraska-Lincoln, Lincoln, NE, USA
}

\begin{abstract}
A modern Municipal Solid Waste (MSW) landfill is a renewable energy resource to produce a significant amount of heat and methane used for generating electricity. However, it is difficult to use those sources effectively because active and post-closure MSW landfills are heterogeneous spatially and temporally and exposed to complex environments with varying pressure and moisture in the landfill. With regard to the prediction of the sources, the analysis of in situ MSW properties is an alternative way to reduce the uncertainty and to understand complex processes undergoing in the landfill effectively. A Hydraulic Profiling Tool (HPT) and Membrane Interface Probe (MIP) measures the continuous profile of MSW properties with depth, including hydraulic pressure, temperature, hydraulic conductivity, electrical conductivity (EC), and concentration of selected volatile organic compounds and methane. In this study, we conducted a series of MIP with HPT tests to investigate the MSW characteristics of a landfill in Nebraska. The results of the test showed an increase in hydraulic pressure and temperature with depth. The EC profile showed a variety of different waste constituents and MIP results showed the methane trapped beneath the top cover. The results in terms of hydraulic properties, temperature and EC obtained from different sites can be used to estimate the waste age and help designing energy recovery systems.
\end{abstract}

\section{Introduction}

Modern MSW landfills are becoming a significant source of renewable energy to generate electricity by using a significant amount of heat and biogas (e.g., methane) produced in landfills. Due to the ongoing biodegradation process of organic material in landfills, methane and heat are generated during the lifetime of a landfill. Heat is generated due to aerobic and anaerobic conversion of cellulose $\left(\mathrm{C}_{6} \mathrm{H}_{10} \mathrm{O}_{5}\right)_{\mathrm{n}}$ to biogas according to the following reactions [1]:

$$
\text { Aerobic: } \begin{gathered}
\left(\mathrm{C}_{6} \mathrm{H}_{10} \mathrm{O}_{5}\right)_{n}+\left(6 \mathrm{nO}_{2}\right) \rightarrow\left(6 \mathrm{nCO}_{2}\right)+\left(5 \mathrm{nH}_{2} \mathrm{O}\right) \\
\Delta \mathrm{H}=-17360 \mathrm{~kJ} /(\mathrm{kg} \text { cellulose })
\end{gathered}
$$

Anaerobic: $\left(\mathrm{C}_{6} \mathrm{H}_{10} \mathrm{O}_{5}\right)_{n}+\left(\mathrm{nH}_{2} \mathrm{O}\right) \rightarrow\left(3 n \mathrm{CH}_{4}\right)+\left(3 n \mathrm{CO}_{2}\right)$ $\Delta H=-1673 \mathrm{~kJ} /(\mathrm{kg}$ cellulose $)$

EPA reports that 107.7 MMT of methane gas was emitted by MSW landfills, which is $16.2 \%$ of the total methane generation in the U.S. [2]. The landfills have been also identified as a source for geothermal heat energy. Studies showed that temperature rises to more than $60{ }^{\circ} \mathrm{C}$ in typical MSW landfills and even passing $120^{\circ} \mathrm{C}$ [3-4]. Coccia et al. [5] demonstrated that adding a plumbing system for heat exchange would not result in a high cost for landfill managers. Their research indicated that this system is a sustainable method to be applied in a practical way [5]. Several case studies showed efficiency and cost-effectiveness of landfillbased geothermal systems that can collect enough heat from waste compared to those of conventional groundbased geothermal heating systems [6].

To predict the resource potential accurately and lead the usage optimally, there have been many efforts to characterize MSW properties in laboratories [10-11]. However, the samples are mostly disturbed and the methods to obtain the properties are time-consuming and costly. It is very difficult to use those sources effectively because active and post-closure MSW landfills are heterogeneous spatially and temporally and are exposed to complex environments with varying pressure and moisture in the landfill. For instance, various chemo physical properties such as moisture content, temperature, hydraulic conductivity, electric conductivity, and concentration vary with the depth of a landfill, as well as time, which results in changing the emission rates of landfill gas and the thermal potential of MSW at different time and places. Thus, the analysis of MSW properties by in situ testing methods is an

\footnotetext{
* Corresponding author: jeun2@unl.edu
} 
effective way to reduce the uncertainty and to better understand complex processes undergoing in the landfill. However, there have been very few efforts to conduct in situ tests to characterize disposed waste in a landfill. Yuen et al. investigated the moisture content of MSW landfills by using a neutron probe in a macroscopic scale [7]. Li and Zeiss used Time Domain Reflectometry (TDR) probes to measure moisture content in a landfill. For this purpose, they calibrated the sensors with MSW and reduced the effect of varying leachate electrical conductivity [8]. Recently, Plocoste et al. [9] used a portable time-of-flight mass spectrometer to measure six different volatile organic compounds (VOCs) in various stages of waste degradation. However, the existing tests in landfills lack feasibility, cost-effectiveness, and convenience. Most cases failed to measure different properties with increasing depth.

Therefore, in this study, we preliminary evaluated various properties of MSW with depth in an operating Nebraska landfill through a series of MIP with HPT tests. In addition, we comparably investigated the properties obtained between the landfill and typical soil layers. Based on the results of the study, we examined MSW characteristics to be used as a potential energy source.

\section{Methodologies}

\subsection{In situ testing apparatus}

A direct injection logger, including a hydraulic profiling tool (HPT) with membrane interface probe (MIP), enables to measure different in situ parameters to characterize the waste properties such as hydraulic pressure, electrical conductivity, hydraulic conductivity, temperature and concentration of selected VOCs and methane in the field (Figure 1).

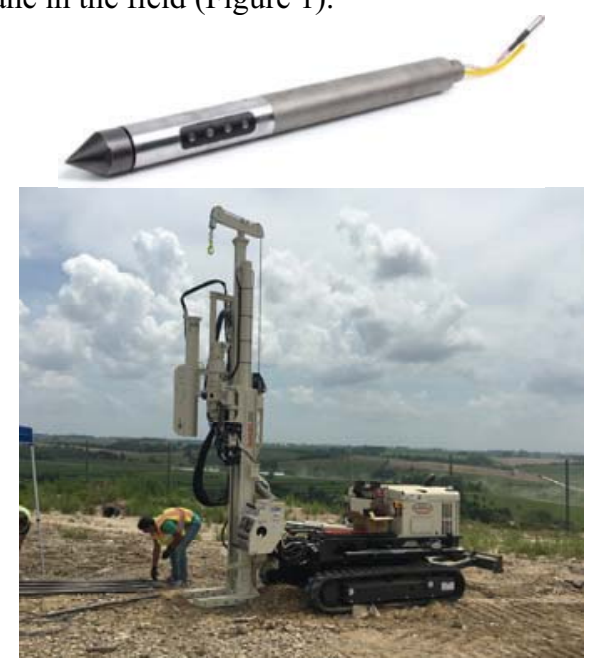

Fig. 1. HPT and MIP equipped on a drilling rigger at the Butler Landfill

An HPT with MIP (MiHPT) consists of a direct injecting cone-device, protective sleeve tubes attached with sensors, and a large drilling machine. HPT sprays fluid at high pressure to adjacent soil as the probe is driven into the subsurface and determines the hydraulic conductivity by detecting the release of hydraulic pressure in the soil. MIP defines continuous profiles of selected landfill gas (LFG) including carbon dioxide and methane in a landfill. MIP consists of two main part, surface instrumentation and downhole probes, as shown in Figure 2, MIP can collect gaseous samples from the subsurface and transfer the sampled vapor to the three detectors equipped on the gas chromatograph (GC) on the surface and give a real-time distribution profile of VOCs with increasing depth. There is a permeable membrane which acts as the interface to the detector line and a carrier gas (e.g., nitrogen) transfers the contaminant to the GC detector. A heater panel is used to increase temperature up to $120^{\circ} \mathrm{C}$ to help with the gas extraction. MIP can work in all types of material and can be applied in unsaturated conditions [12].

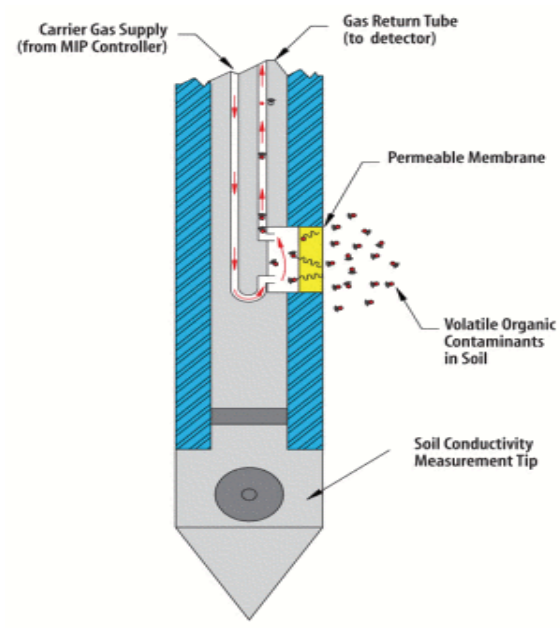

Fig. 2. A schematic view of MIP probe modified from [15]

HPT has a $\sim 700 \mathrm{kPa}$ pressure transducer which is equivalent to approximately $70 \mathrm{~m}$ water head. HPT logs one data for every $15 \mathrm{~mm}$ for HPT pressure, flow and electrical conductivity. HPT also measures hydrostatic pressure under the zero flow condition. The piezometric profile is then used to correct the HPT pressure [12].

\subsection{Experiment procedure}

In this study, three sets of the MiHPT tests were conducted. First, a preliminary test was done at University of Nebraska- Lincoln east campus to obtain a profile for non-contaminated soil layers to a depth of $12.5 \mathrm{~m}$. The results were compared to those obtained from the site in a landfill.

The main two tests were conducted at the Butler County Landfill, Nebraska. The landfill, closely located in the Omaha metropolitan area, accepts municipal solid waste, industrial waste, construction and demolition waste, scrap tires, special wastes including asbestos and non-hazardous contaminated soils. The total depth of the cell was $40 \mathrm{~m}$ and had been active since June 2008. The top interim cover for the site was gently compacted silty clay soils with low plasticity. During the test, weather 
conditions were $32{ }^{\circ} \mathrm{C}$ with no rain in the past 3 days. Two holes were drilled approximately $1.5 \mathrm{~m}$ from each other. The probes were advanced to the depths of $14.6 \mathrm{~m}$ and $17 \mathrm{~m}$. The membrane was left working for around 45 seconds at each depth interval (apprixmately $0.5 \mathrm{~m}$ ) per recommendation from the user manual. In the first tests at Butler Landfill, both MIP and HPT sensors were active along with the heater panel. In the second test, the temperature profile along the depth was obtained as the heater panel on the MIP and water pump on the HPT were turned off. The temperatures were obtained from the thermal gauge attached to the probe. A profile of Electrical Conductivity (EC) was also obtained from both tests.

Contaminants surrounding the penetration are passed through a membrane and conveyed to the detector. Two detectors of photoionization detector (PID) and flame ionization detector (FID) are installed in the GC and are used to detect the presence of organic compounds. Each detector is sensitive to a specific group of compounds. For example, FID detects hydrocarbons and an increase in FID with a small decrease in PID indicates the presence of methane. Before the test is started, a pre-log test is conducted with pure methane and VOCs to calibrate the detecting responses to the compounds.

\section{Results and Discussion}

\subsection{VOC results}

Figure 3 shows the FID and PID profiles obtained from three tests. The results of MIP in the UNL east campus site shows a consistent lack of contaminant down to $6 \mathrm{~m}$ depth. However, a spike in both FID and PID detectors between 6 and $10 \mathrm{~m}$ indicates the presence of VOCs which may be due to the release of a contaminant in that site (Fig. 3a). The MIP results at the Butler landfill show a spike in FID and simultaneous changes in PID ( relatively constant measurements in Fig. $3 \mathrm{~b}$ and clear decline in Fig. 3c) which indicates the presence of methane at the top. Methane has a lower molar mass of $16 \mathrm{~mol} / \mathrm{g}$ compared to $29 \mathrm{~mol} / \mathrm{g}$ for dry air. Methane being lighter than air leads to the placement of methane upwards and becoming trapped beneath the interim soil cap. When the borehole is drilled in the landfill top layer, methane might be easily released into the air through the opening borehole.

However, additional tests at different locations need to be conducted to confirm the methane distribution along with the depth. Furthermore, the test will be conducted in a different season with various ambient temperatures to investigate the variation of the methane production depending on the season.
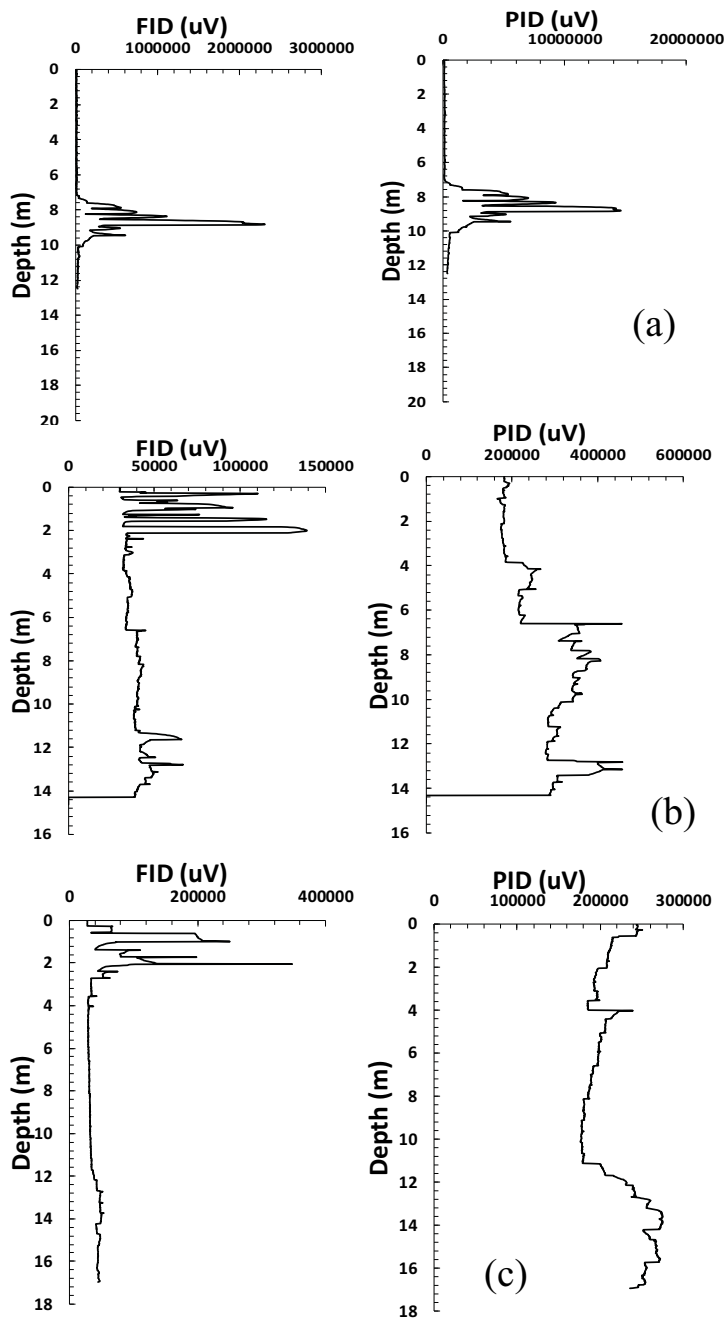

Fig. 3. FID and PID responses for MIP test: (a) the UNL site; (b) the first test at the Butler Landfill; and (c) the second test at the Butler Landfill

\subsection{Temperature profile}

Temperature profile along the waste depth was measured through the second test. Aerobic and anaerobic biodegradation processes inside landfills release heat to the surrounding and due to the low thermal conductivity in MSW waste, heat accumulates and temperatures rise in mid-depth of landfills. As shown in Figure 4, the temperature appears to decrease to the depth of $6 \mathrm{~m}$ which could be due to the accumulation of hot gases on the top surface coupled with raised temperature from sun exposure. However, the temperature increased up to 60 ${ }^{\circ} \mathrm{C}$ as the depth increased from $11 \mathrm{~m}$ to $17 \mathrm{~m}$ which is consistent with previous landfill temperature measurements by other researchers [13-14] The trend of the increasing temperature seems maintained as the depth is deeper. The deeper depth tests need to be conducted to confirm the trend. 


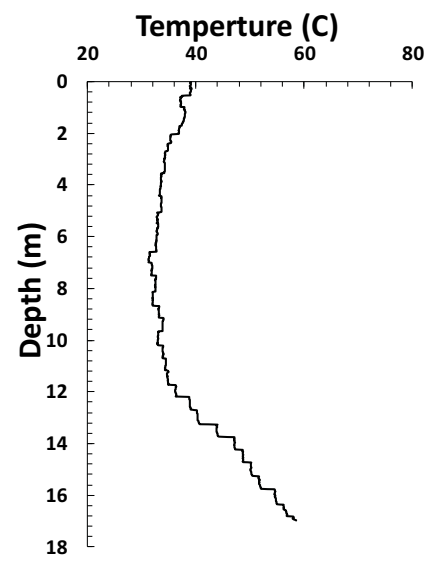

Fig. 4. Profile of temperature

\subsection{Hydraulic pressure profile}

The results of HPT measurement are shown in Figure 5. The pressures generated by injecting water at a relatively constant rate into the material through pumping water in the HPT flow module are shown to change with the penetrating depth during the HPT test. The downhole pressure sensor measured the pressure. The data are logged every $15 \mathrm{~mm}$ and continuously displayed as the probe is penetrated down.
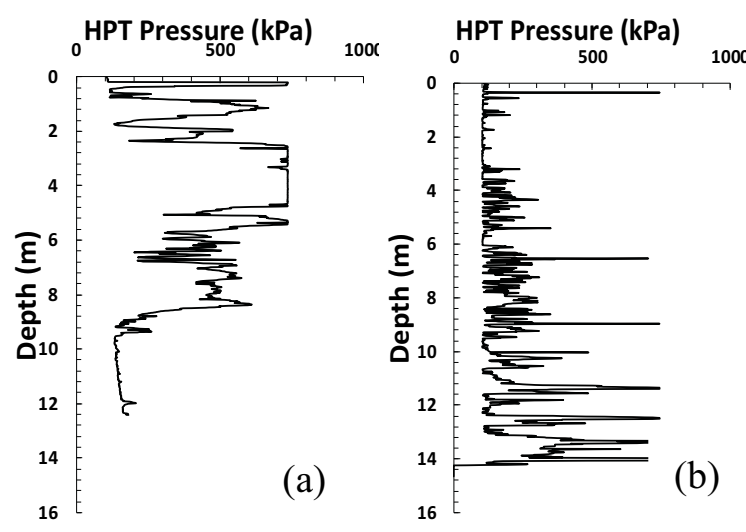

Fig. 5. Profile of HPT pressure: (a) the UNL site; and (b) the first test at the Butler Landfill

HPT profile in Figure 5a obtained from the UNL site shows a fluctuation in pressure with increasing depth in the soil. This result indicated that the type of soil layer changes from silt-clay to sand-gravel lower than $8 \mathrm{~m}$ depth. However, in Figure 5b obtained from the landfill site, the HPT pressure profile shows an increase in pressure by advancement in depth. HPT pressure are less than $200 \mathrm{kPa}$ below $4 \mathrm{~m}$ (average of $117.9 \mathrm{kPa}$ ) and less than 350 at $8 \mathrm{~m}$ depth (average of $163.6 \mathrm{kPa}$ ). However, lower than $8 \mathrm{~m}$ depth shows a significant increase in pressure up to over $700 \mathrm{kPa}$ (average of $243.3 \mathrm{kPa}$ ). Large peaks separated by lower pressures indicate heterogeneity of the waste material where low and high permeability material exist within the profile. Lower permeability of the materials in the MSW results in higher HPT pressure; therefore it can be seen that at depths below 6-7 $\mathrm{m}$ active biodegradation and higher vertical pressure resulted in densification of materials, breakdown of materials and thus smaller void ratio, respectively, which consequently results in higher HPT pressure. From the temperature profile, the higher HPT was observed in the high-temperature layer.

During the HPT test, two dissipation tests were performed at $4 \mathrm{~m}$ and $14 \mathrm{~m}$ depths. At these points, the water pump was turned off and the absolute static pressure graph was obtained. An empirical equation to estimate the hydraulic conductivity was proposed in Eq. (4) by [16] based on field tests and corrected pressure. The corrected pressure was defined considering hydrostatic pressure as:

$$
\begin{aligned}
& P^{*}=P_{\max }-P_{\text {atm }}-P_{\text {hydro }} \\
& K_{\text {est }}=21.14 \times \ln \left(Q / P^{*}\right)-41.71
\end{aligned}
$$

where $P_{\max }$ is the hydraulic pressure, $p_{a t m}$ is the atmospheric pressure measured during pre-test and $\mathrm{P}_{\text {hydro }}$ is the hydrostatic pressure obtained through the dissipation test in psi. $\mathrm{K}_{\text {est }}$ is the hydraulic conductivity in $\mathrm{ft} /$ day estimated by the empirical equation. Hydraulic conductivities have been plotted versus $\mathrm{Q} / \mathrm{P}^{*}$ where $\mathrm{Q}$ is HPT flow. Figure 6 shows the results of the estimated hydraulic conductivity with increasing depth.

The results show that the hydraulic conductivity has an average of $15.12 \mathrm{~m} /$ day between 4.9- and 8-meters depth as where the average between 8 and $14 \mathrm{~m}$ show an average of $11.98 \mathrm{~m} /$ day. The average reduction of hydraulic conductivity is consistent with the lower permeability finding from the hydraulic pressure profile.

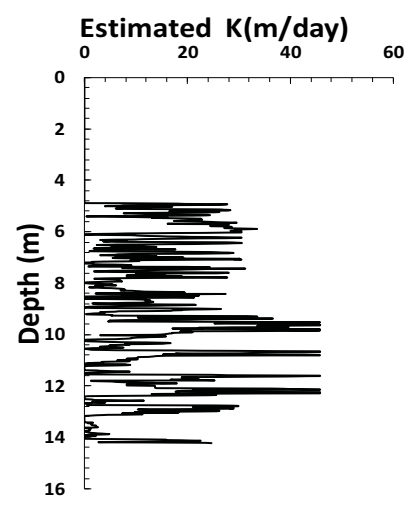

Fig. 6. Estimated hydraulic conductivity

\subsection{Electrical conductivity profile}

Electrical conductivity profile was obtained at a vertical resolution of $0.02 \mathrm{~m}$ [12]. Figure $7 \mathrm{a}$ shows the result for electrical conductivity at the UNL site. Electrical Conductivity (EC) is at very low value due to the absence of material with high electrical conductivity. There were high spikes in the raw obtained profile at the landfill site which indicated the contact of metal debris, slag or highly ionic materials with EC sensor. However, 
obtained EC values are significantly lower than reported EC values of MSW material possibly due to the presence of leachate or small surface area contact. Leachate has a low electrical conductivity, below $150 \mathrm{mS} / \mathrm{m}$ at room temperature, which rises with higher temperature [17].

Upon further analysis, the high spikes in EC curves at the landfill site were considered outlier data. Outliers were calculated using the box plot graph method and were found to be values approximately over than 800 $\mathrm{mS} / \mathrm{m}$. Outliers were excluded from the profile and are shown in Figure $7 \mathrm{~b}$ and Figure $7 \mathrm{c}$.
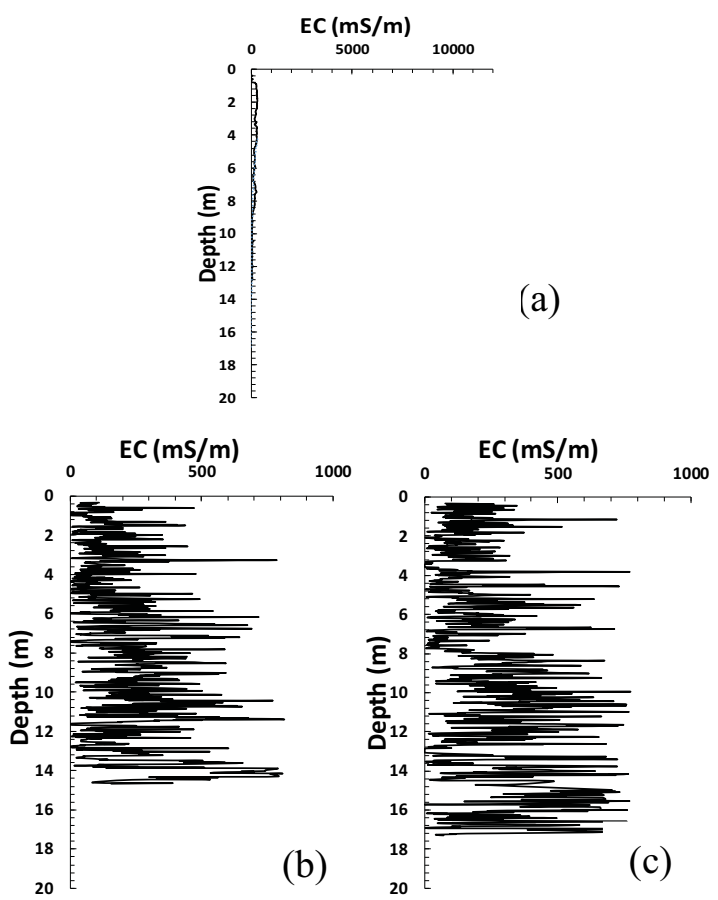

Fig. 7. Electrical conductivity profile: (a) the UNL site; b) the first test at the Butler Landfill; and (c) the second test at the Butler Landfill

$4 \mathrm{~m}$ intervals were selected to find integrated average values of EC. The average EC values show a clear increasing trend which is illustrated in Figure 8.

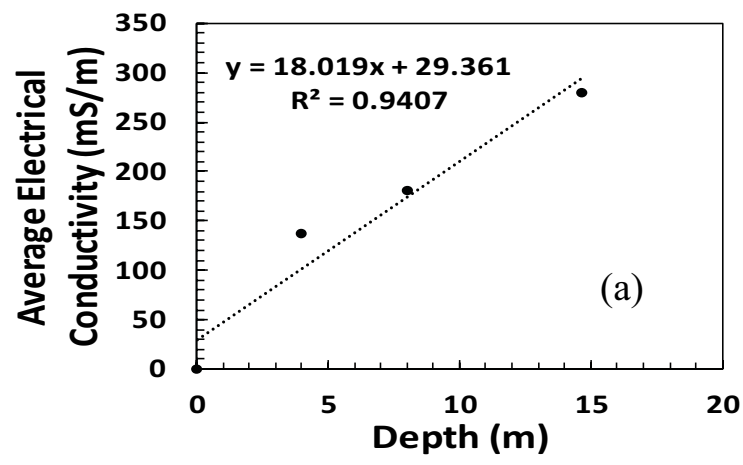

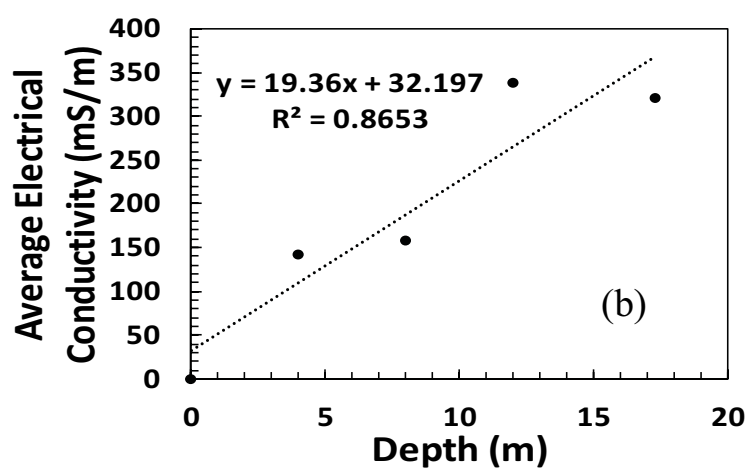

Fig. 8. Average Electrical Conductivity by depth: (a) the first test at the Butler Landfill; and (b) the second test at the Butler Landfill

The EC average results are consistent with the leachates' low electrical conductivity of $150 \mathrm{mS} / \mathrm{m}$. The increase in EC value could be related to both the increase in temperature and a higher density of the material which will result in higher surface contact with the EC sensor. These results also confirm the reliability of the HPT pressure sensor where it shows higher pressure because of densified material at lower depths.

\section{Conclusions}

Three borehole tests were conducted at the UNL east campus and the Butler County Landfill, Nebraska using a MiHPT apparatus to prepare the profile for waste temperature, VOC concentration, electrical conductivity, hydraulic pressure, and estimated hydraulic conductivity. The results show a clear difference of the values between a regular silty clay subsurface material (at the UNL east campus) and MSW (at the Butler landfill). The landfill results showed higher methane concentration at the top layers of a landfill. In addition, the hydraulic pressure and electrical conductivity of MSW showed a strong relationship with the depth. This might present how lower depths have densified material due to higher vertical stress and material breakdown from biodegradation. Higher hydraulic pressure was observed at depth layers with higher temperature.

In future, additional tests at three different landfills at different stages of degradation (Relatively early stage, intermediate stage and post-closure stage) are planned. The comparison of results from different would be handful in estimating the waste age and degradation stage of MSW landfills.

The MiHPT shows the potential to be a cost-effective, convenient and reliable in situ testing apparatus to profile variable changes in a heterogeneous field site upon more data collected from different landfills. The results for temperature, methane concentration, and hydraulic profiles can be useful in improving the design of gas collection systems, leachate collection and recirculation systems and potential thermal energy conversion systems. 


\section{References}

1. M. A. Barlaz, Forest products decomposition in municipal solid waste landfills, $W M, 26(4), 321-$ 333. (2006)

2. https://www.epa.gov/sites/production/files/201902/documents/us-ghg-inventory-2019-main-text.pdf

3. N. Yeşiller, J. L. Hanson, K. B. Kopp, \& E. H, Yee. , Heat generation in municipal solid waste landfills, $W M$, 56, 246-254. (2016)

4. J. T. Powell, T. G. Townsend, \& J. B. Zimmerman., Estimates of solid waste disposal rates and reduction targets for landfill gas emissions, $N C C, 6(2), 162$. (2016)

5. C. J. Coccia, R. Gupta, J. Morris, \& J. S McCartney., Municipal solid waste landfills as geothermal heat sources, $R \& S E R, 19,463-474$. (2013)

6. R. J. Grillo., Energy recycling-landfill waste heat generation and recovery, $C S / R E R, 1(4), 150-156$. (2014)

7. S. T. S. Yuen, T. A. McMahon \& J. R. Styles., Monitoring in situ moisture content of municipal solid waste landfills, $J E E$, 126(12), 1088-1095. (2000)

8. R. S. Li \& C. Zeiss., In situ moisture content measurement in MSW landfills with TDR, $E E$ S, 18(1), 53-66. (2001)

9. T. Plocoste, S. Jacoby-Koaly, R. H. Petit, J. Molinié \& A. Roussas., In situ quantification and tracking of volatile organic compounds with a portable mass spectrometer in tropical waste and urban sites, $E$ T, 38(18), 2280-2294. (2017)

10. K. R. Reddy, H. Hettiarachchi, J. Gangathulasi, \& J. E. Bogner., Geotechnical properties of municipal solid waste at different phases of biodegradation, $W$ M, 31(11), 2275-2286. (2011)

11. D. Zekkos, Jr. E. Kavazanjian, J. D. Bray, N. Matasovic, \& M. F. Riemer., Physical characterization of municipal solid waste for geotechnical purposes, $J G G E, 136(9), 1231-1241$. (2010)

12. http://geoprobe.com/mip-membrane-interface-probe

13. J. L. Hanson, N. Yeşiller, \& N. K. Oettle, Spatial and temporal temperature distributions in municipal solid waste landfills. $J E E, 136(8)$, 804-814. (2010).

14. P. J. Van Geel, \& K. E. Murray, Simulating settlement during waste placement at a landfill with waste lifts placed under frozen conditions. $W M, 46$, 352-361. (2015)

15. T. M. Christy., A permeable membrane sensor for the detection of volatile compounds in soil, $S A G E$ E P 65-72 (1998)

16. W. McCall, T. M. Christy, D. Pipp, M. Terkelsen, A. Christensen, K. Weber \& P. Engelsen., The Hydraulic Profiling Tool (HPT) for Hydrogeologic
Investigation of Unconsolidated Formations, $G M \&$ $R, 34(2), 85-95$. (2014)

17. S. Grellier, H. Robain, G. Bellier, \& N. Skhiri., Influence of temperature on the electrical conductivity of leachate from municipal solid waste, $J H M$, 137(1), 612-617. (2006) 